\title{
Los dos ángeles: Encuentro y desencuentro de dos poemas. Gabriela Mistral y Henry Wadsworth Longfellow*
}

The two angels: Agreement and disagreement between

Gabriela Mistral and Henry Wadsworth Longfellow

Juan Manuel Mancilla Troncoso

Universidad de La Serena. Chile

piedragua@hotmail.com

- 1 fenómeno de la intertextualidad en el opus mistraliano es una posibilidad Ey condición constante de toda su producción. Son múltiples los envíos a distintos códigos y espectros de significación: culturales, religiosos, mitológicos, filosóficos, teosóficos, ámbitos diversos del conocimiento y la cultura en general, sumariamente, referentes difíciles de claudicar y soslayar al momento de leer los textos de la poeta chilena. Dicho proceder, dota a la obra mistraliana de una de las más notables y deseadas características de la poesía y el arte contemporáneo: obra abierta, receptora y productora de sentidos. Apertura y ambigüedad que se despliega y dialoga como un mosaico polisémico cuya fragmentariedad estaría determinada por el tipo específico de lector que a ella llega. En este sentido, Eco (1992) agrega que "la poética contemporánea nos propone una gama de formas que apelan al movimiento de las perspectivas, a la múltiple variedad de las interpretaciones (...) ninguna obra de arte es cerrada sino que encierra una infinitud de lecturas posibles (105).

Estimamos que la inteligencia y "gracia" del programa poético Mistraliano, ante todo se debe a que la poeta tuvo lúcidamente una conciencia crítica y moderna en el sentido rimbaudeano, de lo que es la "abierta" relación en la triada obra lectorinterpretación, "conciencia sobre todo del artista, el cual la elige (la apertura)

*Esta investigación fue desarrollada en el marco del proyecto DIULS PF/07201 de la Dirección de Investigación de la Universidad de La Serena, 2007. Es producto del Seminario Interdisciplinario sobre Gabriela Mistral, desarrollado durante el segundo semestre de 2006, en el marco del curso Semiología de la cultura. Problemas de literatura chilena, MIEL, Depto. Artes y Letras, Universidad de La Serena. 
como programa productivo e incluso ofrece su obra para promover la máxima apertura posible (Eco, 1990: 75). Tomando en cuenta estas consideraciones aproximativas en torno al tema del dialogismo de la poesía mistraliana, el presente trabajo analiza concretamente un diálogo intertextual producido por los poemas "Los ángeles" del poeta norteamericano H. Wadsworth Longfellow" y "Los dos ángeles"1 de la escritora chilena.

Los "Dos ángeles" (Mistral, 1968) es un poema que forma parte de Tala, su tercer libro y que aparece por primera vez a la circulación pública en el año 1938 en la ciudad de Buenos Aires. Específicamente, el poema forma parte de la sección agrupada bajo el título "Alucinación". Se trata de un poema amoroso, místico, de carácter epifánico. Es un texto breve, compacto, agrupado en cuatro estrofas.

"The two angels" es un poema que forma parte de Birds of passege, libro que data de 1877. Forma parte de la sección agrupada bajo el título "Flight the first" ${ }^{2}$, Se trata de un poema de carácter mítico/místico, de carácter epifánico y temible. Es un texto extenso, que contrasta notablemente con el de la chilena; de versos tendientes a lo "narrativo" y agrupados en once cuartetos consonantes.

La lectura sostenida de ambos textos nos ha permitido plantearnos lo siguiente: ¿Cuál es la relación intertextual entre el poema "Dos ángeles" de Mistral y el poema "Los dos ángeles" de Longfellow? ¿Cuáles son las diferencias específicas entre dos textos temáticamente relacionados?

Entonces, el objetivo central de esta nota es evidenciar los puntos de encuentro y desencuentro entre los textos citados, sosteniendo la hipótesis de que la programación textual del poema de la Mistral opera desconstructivamente en la absorción de su pretexto.

\section{ANÁLISIS}

Para la realización de este análisis hemos recurrido al criterio inter e intratextual en el supuesto vinculatorio de los textos. Además, para poder determinar la forma en que la intertextualidad pudiera materializarse en el texto, hemos construido una serie de cuatro cuadros esquemáticos que nos van a permitir evidenciar algunos aspectos que consideramos relevantes.

${ }^{1}$ Para los efectos de nuestro análisis, hemos considerado la traducción del poema realizada por Diocaretz (1999).

${ }^{2}$ Nos parece relevante la evidencia que ambos textos aparecen en una serie e inscriptas al interior de un texto mayor. Es significativa, además, la coherencia de la relación semántica de las institulaciones, a saber, "Alucinación" y "El primer vuelo", ambas dentro del campo semántico de lo aéreo o fuera del espacio terráqueo y/o de lo ligado a lo consciente. 
Aspecto temático. El factor principal que justificaría la intertextualidad entre los textos. Para determinar con claridad este aspecto y a modo de evidencia, hemos procedido a categorizar aplicando los siguientes criterios:

Tabla 1. Aspecto temático

\begin{tabular}{|l|l|l|}
\hline Criterios & Longfellow & Mistral \\
\hline PA & Los dos ángeles & Dos ángeles \\
\hline BAC & Uno de la Muerte y uno de la Vida & $\begin{array}{l}\text { el Ángel que da el gozo } \\
\text { y el que da la agonía }\end{array}$ \\
\hline SPP & $\begin{array}{l}\text { Reconocí la agonía sin nombre, } \\
\text { El terror y el temblor y el dolor }\end{array}$ & $\begin{array}{l}\text { y me les doy como alga } \\
\text { a la ola, contrita. }\end{array}$ \\
\hline PVA & $\begin{array}{l}\text { Susurro una palabra cuyo sonido era } \\
\text { como la muerte }\end{array}$ & $\begin{array}{l}\text { y anudaron el nudo } \\
\text { de la muerte con la vida! }\end{array}$ \\
\hline A & $\begin{array}{l}\text { Pero uno llevaba corona de amaranto } \\
\text { Y el otro de asfódelos, cual copos de } \\
\text { luz. }\end{array}$ & $\begin{array}{l}\text { si el de color de llama } \\
\text { o el color de ceniza }\end{array}$ \\
\hline
\end{tabular}

PA: presencia angélica. BAC: Binomio angélico contradictor. SPP: Sensaciones producidas por su presencia. PVA: Propósito de la visita angélica. A: Apariencia.

Aspecto semántico. Consiste en agrupar una serie de lexemas que forman parte del texto y que pueden reunirse bajo significados o connotaciones discordantes. Para ello hemos utilizado las siguientes categorías:

A) Campo semántico vinculado a las asociaciones topo-espaciales. Es un factor clave para constatar la hipótesis de que el texto base (hipotexto) es desconstruido en la absorción concreta que produce el texto mistraliano.

Tabla 2. Resultado campo semántico de las asociaciones topo-espaciales entre los textos

\begin{tabular}{|l|l|}
\hline \multicolumn{1}{|c|}{ Textos } & \multicolumn{1}{c|}{ Resultados } \\
\hline Longfellow & $\begin{array}{l}8 \text { menciones a situaciones espaciales referentes al espacio humano y } \\
\text { terrestre. } 4 \text { menciones a la palabra puerta y } 4 \text { a la palabra casa. }\end{array}$ \\
\hline Mistral & $\begin{array}{l}1 \text { mención a una situación espacial. No incurre referencial terráqueo } \\
\text { habitado por humanos, sólo el cielo. }\end{array}$ \\
\hline
\end{tabular}


B) Campo semántico vinculado a las asociaciones crono-temporales. Es otra variable clave para sostener la relación de existencia y/o co-presencia del hipotexto del poeta norteamericano en el texto mistraliano.

Tabla 3. Campo semántico de la asociación crono-temporal

\begin{tabular}{|l|l|}
\hline \multicolumn{1}{|c|}{ Textos } & \multicolumn{1}{c|}{ Resultados } \\
\hline Longfellow & $\begin{array}{l}\text { Una referencia al momento en que los seres alados se presencian, el } \\
\text { alba, el amanecer, la aurora: "Dos ángeles... al romper la mañana } \\
\text { pasaron" }\end{array}$ \\
\hline Mistral & $\begin{array}{l}\text { De igual manera, el texto mistraliano sitúa temporalmente la } \\
\text { aparición /contemplación de los seres angélicos al romper el alba: "Yo } \\
\text { sé, cuando amanece" }\end{array}$ \\
\hline
\end{tabular}

Aspecto formal. Consiste en describir la estructura o tipología textual que conforman ambos textos, que de igual manera pueden constituirse como criterio significativo discordante como argumento para poder constatar nuestra hipótesis. Para ello hemos convenido utilizar (interesadamente) los siguientes criterios de aproximación:

Tabla 4. Aspectos formales

\begin{tabular}{|l|l|l|}
\hline Criterios & Longfellow & Mistral \\
\hline CE & 11 Cuartetos & 4 Estrofas irregulares \\
\hline TR & Consonante & Blanca \\
\hline TV & De tendencia a la extensión & De tendencia a la brevedad \\
\hline TP & Prosístico/ prosopográfico & Críptico/no descriptivo \\
\hline TA & Temeroso/dudoso & Regocijo/seguridad \\
\hline ALP & Enunciativa & Carmínica \\
\hline FCP & Referencial & Emotiva \\
\hline
\end{tabular}

CE: Constitución estrófica. TR: Tipo de rima. TV: Tipo de verso. TP: Tipo de poema.

TA: Temple anímico. ALP: Actitud lírica predominante. FCP: Función comunicativa predominante. 


\section{INTERPRETACIÓN}

\section{Puntos de encuentro}

Es efectiva la presencia de dos ángeles en ambos textos. Estos mensajeros, en su étimo griego, mediadores entre el cielo y la tierra (Becker, 1996), a través de los cuales se sirve Dios para hacer cumplir sus designios en la tierra. Sus apariciones son hechos inefables, por ello es que los ángeles son el símbolo de lo invisible, conjunción de fuerzas ascendentes y descendentes entre el creador y las criaturas. Los ángeles de ambos textos se nos muestran en la lectura como culturalmente en Occidente se les conoce: una aparición, una epifanía. Su naturaleza dual, el principio de contradicción que los rige, también se manifiesta en ambos textos: arriba/abajo, mal/bien, blanco/negro. Este carácter contradictorio, dualístico y escindido de los ángeles es manifiesto por ambos textos. De la heterogeneidad o tipos angélicos que han sido representados por el imago religioso cristiano/ occidental; caídos, guardianes, tutelares, exterminadores, ambos textos recortan ese ámbito al de la muerte y a los dadores de la vida:

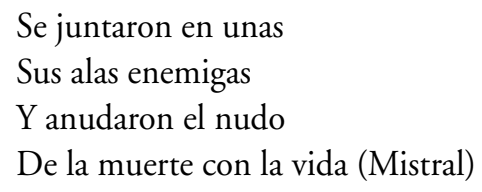

Dos ángeles, uno de la Muerte y uno de la Vida

Por nuestro pueblo al romper la mañana pasaron (Longfellow)

En jerarquía, los serafines son los más cercanos a Dios y su trono y llevan cirios encendidos. Querubines son los que llevan símbolos dorados y sabiduría. En el texto de Longfellow no se puede determinar la naturaleza de sus ángeles, tal vez el ángel de amaranto pudiera ser tanto serafín como querubín, pues los símbolos que nos entrega la descripción bien pueden adjudicarse a estas dos categorías: "Pero uno llevaba corona de amaranto, como llama (...)".

En el código simbólico esta flor es signo de inmortalidad y en la iconografía se representa como una doncella que lleva en sus manos un ramo y un disco de oro (Becker, 1996). Tal signo nos hace pensar que por la comparación "como llama” es atribuible la condición de Querubín, ya que éstos llevan símbolos dorados. El envío intertextual del texto mistraliano opera de similar forma en cuanto a las descripciones "físicas" de los ángeles de Longfellow: "si el de color de llama / o el color de ceniza” (Mistral). En este ángel principia el dinamismo, 
la constancia cambiante, lo fluyente, lo erótico, mientras que en el otro, "el de asfódelos cual copos de luz", que en la antigua tradición griega era una planta que ofrendaban a sus muertos, y que en el texto deviene en el principio tanático con la inclusión de un adversativo que opone la similitud antes reconocida por el hablante:

Tenían la misma apariencia y actitud, Semejantes rasgos y ropas blancas

Pero uno llevaba corona de amaranto, como llama, Y el otro de asfódelos, cual copos de luz (Longfellow)

Sobre el momento en que irrumpen en el cielo, ambos textos están situados al alba. Ambas apariciones son al amanecer, momento en que la res natura también está en ese trance de ser no siendo (Valery), como la natura angélica. Ambos hablantes son testigos de la epifánica aparición que tiene lugar en el fotoinstante de la aurora:

Yo sé, cuando amanece,

cual va regirme el día, (...) (Mistral)

(...) Por nuestro pueblo al romper la mañana pasaron;

El alba venía en sus semblantes, y abajo,

Surgían plumajes de humo funéreos de las casas sombrías (Longfellow)

\section{Puntos de desencuentro}

La apertura textual del poema mistraliano es una negación que resulta ambigua tanto en su disposición o ubicación versátil espacial como por su indeterminación semántica: "No tengo un solo Ángel / con ala estremecida (...)". Sin embargo, el lexema "solo" funciona tanto en su dimensión adverbial de cantidad como en su designación adjetival de condición de soledad. La relación mencionada cambia notablemente luego que por efecto de lectura se liga el segundo verso y el sentido del primero se completa y complementa. Además, manifiestamente, el sujeto de la enunciación declara que es mecida por estos dos seres. Los ángeles mueven, se mecen. Interesante resulta también aquí el procedimiento mistraliano en el empleo de lexemas contradictorios o figuras bimembres en oposición, a saber: mar /orilla, figuras que en su contracción verbal designan y devienen en el plano semántico como la oscilación constante de casi la totalidad de la obra mistraliana. Poesía del conflicto (Vergara, 1985: 
72) que ansía un deseo, pero que no se consuma. Coincidimos en lo de conflictivo, sin embargo, en este poema, el sujeto consuma una acción, que agregaríamos es gozosa y resuelve la tensión del conflicto de forma feliz; el hablante se deja asir, permite recogerse por los ángeles, se deja mover por estos dos seres celestes.

Estos ángeles son los que invitan a ser partícipe de la epifanía en que los dos hacen del nudo de la muerte un nudo de vida. En este sentido, no coincidimos con las aseveraciones que de la poesía de la Mistral realiza Gastón von dem Bussche (2001), al caracterizarla como de tendencia trágica y sufriente: "La poesía de la Mistral no se conformará jamás en otro plano, no logrará aplacarse entre límites apaciguadores y demarcadores. Esta necesidad de lo Absoluto la lleva de una experiencia trágica del amor a un sentimiento religioso del mundo y el ser y al sentido final de la liberación por la muerte" (103). Por el contrario, vemos en este poema de Tala un acceso gozoso al amor, una contemplación y consumación glorificada en lo erótico. Seguimos a Falabella (2006) cuando insiste en que se realicen lecturas de la Mistral enfocadas hacia los espacios del goce. Consideramos así, que la resolución de este poema es de carácter erótico: "Yo sé, cuando amanece, / cual va regirme el día (...) y me les doy como alga / a la ola, contrita" (...) me mecen como al mar, / mecen las dos orillas".

El tropo erótico opera como un lugar paradójico donde la transgresión de la norma se materializa. (...) Funciona donde el tráfico de la continuidad entre la vida y la muerte, tráfico erótico y suspendido en el tiempo, contagia y asedia a los y las lectoras. (...) el erotismo en la poesía de Gabriela Mistral se constituye como una fuerza simbólica que irrumpe con nuevos lenguaje a patrones anteriores (...) tensionándolos y trabajando sobre sus límites (Falabella, 2006: 352).

Aquí se produce uno de los desencuentros más notables entre los textos, ya que el sujeto de la enunciación de la Mistral no siente miedo y participa de lo que sucede en el cielo. En cambio, el sujeto de Longfellow se nos desvela terráqueo e intranquilo, mientras testifica en el alba el vuelo de los ángeles. Se muestra aterrado ante la posibilidad de que el ángel de la muerte lo rapte.

Les vi tomar un descanso en su viaje celestial;

enseguida dije, con reservada duda y profundos temores

¡no palpites tan fuerte, corazón, no sea que

el sitio donde tus seres amados reposan traiciones! 
Reconocí la agonía sin nombre,

El terror y el temblor y el dolor

Que a menudo se me habían aparecido

y que ahora retornaban con fuerza tríplice.

(...) dije, con reservada duda y profundos temores

"¡no palpites tan fuerte, corazón, no sea que

el sitio donde tus seres amados reposas traiciones!" (Longfellow).

Mientras que en el texto de la Mistral, el sujeto de la enunciación goza del encuentro con los seres alados. A través de uso del verbo en pasado evidencia haber ya participado en la consumación de algo junto a ellos en aquella mañana epifánica:

Solo una vez volaron

con las alas unidas:

el día del amor,

el de la epifanía (Mistral).

Luego, en Longfellow, los ángeles descienden a la Tierra, uno a la casa del testigo (el de vida) y el otro, el del mal, el de la muerte, a la habitación de una de las casas vecinas del pueblo. El de la muerte arrebata el alma de un ser para llevarlo consigo. Luego, el sujeto de la enunciación apela de forma desafiante al lector, sobre la posibilidad de que un ángel pueda aparecer ante "nuestras" vidas; finalizando con una pregunta retórica:

No vino a la mía, amigo, sino a tu puerta,

el ángel de la corona amarantina,

Haciendo una pausa, descendió, y con voz divina (...)

Susurro una palabra cuyo sonido era como la muerte

"¿Quién, por tanto, al creer esto, se atreve o desea,

cerrar ante sus mensajeros la puerta...? (Longfellow).

Sobre este punto podemos comentar que el desencuentro producido entre los textos es notablemente desconstructivo en la concreción del poema mistraliano, ya que en él no existe la apelación al lector, sino que el texto se abre, se muestra visualmente como una invitación testificadora, un participar de la lectura como intromisión/introducción efectiva y corporal al texto. Simultáneamente, en la lectura visual del mismo, por su especial conformación estrófica. La situación 
del lector está en una relación/posición de testigo de lo que sucede entre los ángeles y el sujeto de la enunciación. Un proceder similar, nota Falabella(2006) en su lectura sobre el poema "Íntima":

Otra manera de trabajar la vertiginosidad erótica se produce a través de la escritura en primera persona. Ha un acto doble de desnudar los sentimientos prohibidos, el de los amantes como unidad [el remarcado es nuestro] (...) el verso atrapa vertiginosamente al lector convirtiéndolo en un espectador amoroso (Falabella, 2006: 348).

Destacamos la especial y notable disposición/distribución del poema mistraliano, puesto que visualmente su conformación estrófica: 8644 que si mirado el texto siguiendo una orientación desde abajo hacia arriba, deviene en una escalera formada por ascendentes peldaños versales que invitan al lector a subir hasta el cielo y llegar a la cima junto con los dos ángeles. Distinto del poema del inglés ya que allí se involucra al lector de manera intimidante, de manera que el sujeto de la enunciación advierte en tono irónico que "No vino a mi a la mía, amigo,/ sino a tu puerta el ángel de la corona amarantina".

El texto de Longfellow podríamos llamarlo poema-relato, dado que la lectura se ofrece como la narración (poética) de un hecho sucedido, de una impresión que debe ser "contada". En sí, el texto se abre cuando al amanecer sucede la aparición de dos ángeles, que son observados con asombro por un testigo. Luego, se detienen en su viaje alado y al testigo le comienzan a invadir temores sobre lo que harán con él.

\section{RESULTADOS}

El análisis realizado ha demostrado que la relación del envío y diálogo intertextual es controversial. La concretización del poema mistraliano es descontructiva respecto de la absorción de su hipotexto inglés. El número de encuentros es evidentemente menor a la cantidad de desencuentros que se producen entre ellos. Textos que por su temática similar y que a simple vista y superficialmente, pareciera se comportarían de la misma manera. En conclusión, los textos terminan más distanciados que (con) fundidos. A continuación, se evidencian los puntos de encuentro y desencuentro entre los textos. 
Tabla 5. Puntos de encuentro y desencuentro

\begin{tabular}{|c|c|c|c|}
\hline \multicolumn{2}{|c|}{ Encuentros } & \multicolumn{2}{c|}{ Desencuentros } \\
\hline $\begin{array}{c}\text { Los dos ángeles } \\
\text { Longfellow }\end{array}$ & $\begin{array}{c}\text { Dos ángeles } \\
\text { Mistral }\end{array}$ & $\begin{array}{c}\text { Los dos ángeles } \\
\text { Longfellow }\end{array}$ & $\begin{array}{c}\text { Dos ángeles } \\
\text { Mistral }\end{array}$ \\
\hline Dos ángeles & Dos ángeles & Terror & Gozo \\
El alba & El alba & Muerte & Vida \\
Apariencia & Apariencia & Separados & Unidos \\
& & Resistencia & Entrega \\
& & Inseguridad & Seguridad \\
& & Terráqueos & Aéreos \\
\hline
\end{tabular}

\section{CONCLUSIONES}

De los resultados mostrados, del análisis e interpretación, podemos inferir las siguientes conclusiones:

1) La posibilidad de leer los poemas "Los dos ángeles" y "Dos ángeles" en relación intertextual es efectiva. Dicha vinculación puede comprenderse en un diálogo que correlaciona los textos en una dialogía polémica. Longfellow otorga al sujeto de la enunciación un padecimiento, mientras que en el texto mistraliano, la resolución última es feliz y gozosa de ese misterio celestial. Otra vez, Mistral se nos revela contradictoria y transgresora ${ }^{3}$ más aun, cuando aparentemente (homología/analogía) en la superficie, los textos se mimetizan. Sus ángeles no bajan a la tierra; invierte la tradición de las apariciones angelicales. No son los dos ángeles los que se le aparecen a un humano, sino lo humano se presencia ante esta danza supracósmica. Invitan a ser partícipe de la epifanía en que tres desatados del nudo de la muerte se atan al des/nudo de la vida. El texto de la Mistral invierte el sentido de muerte manifestado en el hipotexto inglés. Retórica y goce de la erótica, triunfo de Eros sobre Tanatos.

2) El análisis aquí propuesto nos ha permitido evidenciar ciertas características específicas que definen la relación entre el poema de la Mistral con el de

${ }^{3}$ Recordamos aquí impostergablemente, quizás, uno de los más estremecedores poemas dedicados a la poetisa: la portentosa "Elegía a Gabriela Mistral" de Enrique Lihn: "Dirán que se ha dormido para siempre, dirán /que un ala color fuego y otra color ceniza / el ángel de su voz baja por ella $(\ldots)$ ". 
Longfellow. Recordemos que la mayoría de los ejemplos que propusimos como puntos de desencuentro están operando en campo semántico entre "Los dos ángeles" de Longfellow y los "Dos ángeles" de Mistral, mientras que en los ejemplos que propusimos como puntos de encuentro predominaron, evidentemente, aquellos en los que el diálogo se hacía más directo o específico a nivel superficial, incluso pudiendo (pidiendo) confundir a un "despreocupado" lector. Si estas apreciaciones son extensibles en el poema "El ángel guardián" de Robert Browning, pueden ser motivo para otro trabajo en que desarrollemos esta misma línea teórica.

3) En este estudio dimos cuenta de cómo contribuye la teoría intertextual sobre la actualización de los potenciales de sentidos presentes en una obra, pues, concluyendo que el texto de la Mistral no se reduciría o se resiste a ser solamente un poema más que revela la americanidad de Tala. Si bien es cierto que esto no es nuevo para la crítica especializada, tampoco es equívoco que la intertextualidad aquí propuesta es, por lo menos, novedosa. Por esto mismo, creemos que el análisis no deja de resultar una alternativa legítima al momento de aproximarse a la multiplicidad de sentidos que la obra de Mistral apertura.

\section{REFERENCIAS}

Becker, Udo. (1996). Enciclopedia de los símbolos. Barcelona. Robinbook. Diocaretz, Myriam. 1999. Aire y ángeles. Madrid: Grijalbo/Mondadori.

Eco, Umberto. 1990. Lector in fábula (la cooperación interpretativa en el texto narrativo). Barcelona: Editorial Lumen.

1992. Obra abierta. Trad. Roser Berdagué. Buenos Aires: Planeta.

Falabella, Soledad. 2006. “¿Qué está en el beso y no es el labio? Placer, ética erótica y lengua maternal en un poema de Desolación de Gabriela Mistral”, en Mapocho II semestre.

Longfellow, Henry Wadsworth. 1877. Birds ofpassage. Ebook: The Project Gutemberg. [En línea] Disponible en http://www.gutemberg.net. [Consulta: 13/10/2007).

Mistral, Gabriela. 1968. Poesías completas. Margaret Bates (ed). Madrid: Aguilar. 4ta edición.

Vergara, Sergio. 1985. "Lectura de la copa", en Estudios Filológicos 20, pp. 69-82.

Von dem Bussche, Gastón. 2001. "Visión de una poesía”, en Mapocho 49. 